\title{
A Corpus-Based Study on the Application of Connectives in Chinese College Students' English Writing
}

\author{
Chunping Nan
}

\author{
Northeast Petroleum University, Daqing, China \\ *Corresponding author. Email: 71542312@qq.com
}

\begin{abstract}
Making use of self-built corpus and retrieval software AntConc, this paper first makes a comparative analysis of the use of connectives by non-English majors in Northeast Petroleum University and English native college students, and then compares the use of connectives by these Chinese students in CET-4 simulated compositions in the previous year and the following year. The findings show that the students in Northeast Petroleum University have a strong awareness of using different kinds of connective words to help achieve the well cohesion of the article in its content, which is especially true in the use of connectives that express juxtaposition, causation, contrast, concession, and certainty. However, compared with British students, their frequency of using appositives and transitions is insufficient and the application of summary transitions is too frequent. Meanwhile, after a year of study, the students were most likely to use causal connectives and concessional connectives. There were a number of reasons why the number of connectives students used in their writing after one year had not been increased, but decreased. This study will be available for some enlightenment for college students' English learning and teachers' teaching in future.
\end{abstract}

Keywords: Corpus, English writing, Connectives, Non-English majors.

\section{INTRODUCTION}

By far, Chinese college students still consider writing to be the most difficult of the four basic English language skills. They face a variety of problems in writing, including vocabulary, grammar, discourse cohesion and so on. Some studies have shown that among all kinds of problems, improper organizational cohesion seems to be the biggest problem in Chinese college students' advanced writing [1-3]. Halliday and Hasan believe that good writing is not simply about arranging sentences but about connecting them. Li found that her students lacked connectives and effective cohesion in their writing, so they could not construct a coherent text. She stressed that the lack of logical cohesion leads to the lack of coherence in the whole article, which is common in college students' English writing.

Connectives play an important role in the context of an article. Although there are more and more studies on connectives, researchers do not give a clear definition. Different scholars use different terms for words or phrases that produce logical relationships [4]. Halliday and Hasan believe that connectives belong to cohesion, together with reference, ellipsis, substitution, lexical cohesion and conjunction. Bourne points out that a connective is a word or phrase used to indicate a relationship of meaning. Biber et al. call connectives connective adverbs. In this study, connectives refer to words or phrases used to indicate the relationship between different components and show logical relationships.

The importance of connectives has attracted great attention from experts and scholars at home and abroad. Some researchers compare and analyze the compositions of Chinese English learners with those of native English learners. Some are devoted to comparing the written works of English learners at different levels. Others study the relationship between the use of connectives and writing quality [5-6]. Granger and Tyson conducted a comparative study on the use of connectives in articles between English learners in France and native English learners. The study found that French learners tended to use more connectives to illustrate or emphasize an opinion, and fewer connectives to represent contrast or to make logical 
arguments. Allard \& Ulatowska conducted a study on 30 native English speaking students to find out the relationship between the frequency of connectives application and the quality of writing. They found that works that used more cohesive devices were of relatively higher quality. At the same time, domestic scholars have also done a lot of research on the connectives [7]. Li Xiaoxia studied the use of connectives in argumentative discourse. The participants were English majors, and she found that connectives play an important role in textual clarity. Based on the corpus of English majors, Zhao Min and Feng Xia conducted a study. Their research compares the use of adversative connectives in English writing by English majors in normal universities and those in foreign language colleges. The results show that English majors in foreign language colleges make fewer mistakes than those in normal colleges.

Although there has been a lot of research on connectives, further research is still urgently needed. Most of the previous studies focused on the current situation of the use of connectives, and few of them made long-term observations on the use of connectives in students' writing while comparing domestic and foreign corpora [8-9]. This study will make a comparative analysis on the differences in the use of connectives in writing between English majors in Northeast Petroleum University and British college students, and make a comparative analysis on the use of connectives in college English writing of this group of students in the previous year and the following year. This study will make English teachers and English learners realize the importance of connectives in English writing and provide reliable data and reference materials for further research on cohesion in English discourse.

\section{METHODOLOGY}

\subsection{Research Problems}

The concrete problems studied in this paper are as follows:

(1) What are the similarities and differences in the use of English connectives between non-English majors in Northeast Petroleum University and native English speakers in Britain? Analyze the reasons for the differences.

(2) In English writing, what are the similarities and differences between the use of English connectives by non-English majors in Northeast Petroleum University one year ago and one year later? Analyze the reasons for the differences.

\subsection{Theoretical Framework}

The theoretical basis of this study is Halliday and Hasan's cohesion theory (1976). Halliday and Hasan concluded cohesion theory, whose theoretical framework is represented by such cohesive devices as reference, ellipsis, substitution, conjunction and lexical cohesion. Their theory of textual cohesion involves five categories: reference, substitution, ellipsis, conjunction and lexical cohesion. Since the publication of Cohesion in English co-authored by them, domestic and foreign scholars have carried out researches on cohesion and coherence at different levels [10]. Researchers have conducted in-depth discussions on the theory of textual cohesion from different perspectives and with different methods, so as to continuously develop and improve it. The book explains the theoretical orientation, scope and position of the concept of cohesion in linguistic systems and contexts. It also puts forward the classification of cohesion devices as grammatical cohesion, including anaphora, substitution, ellipsis, conjunction, lexical cohesion, including repetition, synonym and discusses the meaning of cohesion. Halliday pointed out that cohesion is a semantic concept, which refers to the semantic connection between linguistic components in a text, or the relationship between one component in a text and another that can be interpreted with each other. Cohesion occurs when the meaning of one component of a text depends on the interpretation of another component. Huang Guowen and other scholars introduced cohesion theory into China. And $\mathrm{Hu}$ Zhuanglin put forward a multi-level model of cohesion and coherence. In his book Textual Cohesion and Coherence, Hu Zhuanglin takes transitivity as one of the cohesive devices to expand the scope of structural cohesion.

\subsection{Research Object}

Quirk et al. divide connectives into seven types. Based on the classification of connectives by Quirk et al., this study divides connectives into nine types. They denote summation, juxtaposition, apposition, causation, inference, contrast, transition, concession, and determination respectively. Considering the practicality of teaching, this paper, from the perspective of operation, finally determines the research object of this paper, namely the connectives studied in this paper, and the detailed classification is shown in the following table: 
Table 1. Classification of connectives in this study

\begin{tabular}{|c|c|}
\hline Classification & Typical Words \\
\hline Juxtaposition & $\begin{array}{l}\text { first(ly), second(ly), third(ly), first of all, in particular, at first, on the } \\
\text { one hand } \cdots \text { on the other hand, also, next, to begin with, then, finally, } \\
\text { at last, and, too, besides, as well, equally, in the same way, moreover, at } \\
\text { the same time, furthermore, in addition }\end{array}$ \\
\hline Summation & $\begin{array}{l}\text { (all) in all, in short, in a nutshell, general speaking, therefore, to sum up, } \\
\text { thus, in a word, in general, in conclusion }\end{array}$ \\
\hline Apposition & $\begin{array}{l}\text { that is, namely, in other words, for instance, such as, that is to say, } \\
\text { for example }\end{array}$ \\
\hline Causation & $\begin{array}{l}\text { because, since, due to, as a result of, because of, } \\
\text { so, consequently, hence, as a consequence, somehow, accordingly, } \\
\text { thus, as a result, as, therefore }\end{array}$ \\
\hline Inference & in other words, in that case, otherwise, else \\
\hline Contrast & $\begin{array}{l}\text { however, instead, then, in contrast, nevertheless, rather than, on the } \\
\text { other hand, instead of, on the contrary }\end{array}$ \\
\hline Transition & now, well, in the meantime, meanwhile, by the way \\
\hline Concession & still, although, even though, though, even if, in spite of, after all \\
\hline Determination & $\begin{array}{c}\text { of course, actually, as a matter of fact, in effect, incidentally, in fact, } \\
\text { apparently, indeed }\end{array}$ \\
\hline
\end{tabular}

\subsection{Corpus Construction}

Corpus I: The author selects 300 CET-4 simulated compositions (about 150 words per composition) of non-English major students from Northeast Petroleum University in 2020 and 300 CET-4 simulated compositions of those students in the following year to make the self-built corpus I, which is equivalent to the words in corpus II. The reason for choosing CET-4 mock composition is that these composition propositions and requirements are in line with the requirements of CET-4 syllabus formulated by college English Examination Committee.

Corpus II: The author selects part of argumentative essays of British college students from the LOCNESS corpus to build corpus II with 95695 words. These essays meet the requirement on the middle and advanced writing level [11-13], and are equivalent to the college English composition writing level, and also similar in content.

\subsection{Research Methods and Steps}

Firstly, based on the classification of connectives by Quirk et al., we divide connectives into nine types, and then select 88 representative connectives and phrases. Secondly, we select 300 CET-4 simulated compositions (about 150 words per composition) of non-English major students from Northeast Petroleum University in 2020 and 300 CET-4 simulated compositions of those students in the following year to make the self-built corpus I. The author selects part of argumentative essays of British college students from the LOCNESS corpus to build corpus II with 95695 words. These essays meet the requirement on the middle and advanced writing level, and are equivalent to the college English composition writing level, and also similar in content. Thirdly, AntConc is used to retrieve the locked connectives to determine the frequency of the 88 locked connectives in the two self-built corpora. Fourthly, a questionnaire was designed on base of the previous research and relevant literature. The questionnaire aims to understand students' attitude towards writing and their understanding of connectives. It consists of 20 questions and four parts: The first three questions aim to investigate students' attitude towards English learning and writing. Questions 4 to 13 are about students' textual awareness and knowledge of specific connectives. The next three questions are to investigate whether English teachers give correct guidance on the use of connectives in teaching. The last four questions 
are designed to find the correct and appropriate way to write. Finally, the author collected 120 valid questionnaires for research and analysis.

\section{RESULTS AND DISCUSSION}

Table 2. The Overall Frequency of Connectives in the Two Corpora

\begin{tabular}{|c|c|c|}
\hline & Corpus I & Corpus II \\
\hline Scale (Total Words) & 81326 & 95695 \\
\hline Frequency of Connectives & 3935 & 2794 \\
\hline Percentage & $4.84 \%$ & $2.92 \%$ \\
\hline
\end{tabular}

Table 2 shows that in corpus I which is with a scale of 81326 words, the frequency of connective words occurrence is 3935 times, accounting for 4.84\%; while in corpus II, with a scale of 95695 words, the frequency of connective words is 2794 times, accounting for $2.92 \%$. It can be seen that connectives are commonly used in two corpora and play an important role in
After searching the locked connectives and phrases in corpus I and corpus II, the frequency and percentage of their occurrence in the two corpora are shown in Table 2: textual cohesion. The frequency of connectives in corpus I is $4.84 \%$, which is higher than that in Corpus II $(2.92 \%)$, indicating that Chinese college students have a strong awareness of using connectives in their writing. categories in the two corpora was further made, as shown in Table 3: Statistics on the frequency of connectives of different

Table 3. Frequency and Percentage of Connectives of Different Categories in the Two Corpora

\begin{tabular}{|c|c|c|c|c|}
\hline \multirow{2}{*}{ Category } & \multicolumn{2}{|c|}{ Corpus I } & \multicolumn{2}{c|}{ Corpus II } \\
\cline { 2 - 5 } & $\begin{array}{c}\text { Frequency of } \\
\text { Connectives }\end{array}$ & $\begin{array}{c}\text { Percentag } \\
\mathrm{e}\end{array}$ & $\begin{array}{c}\text { Frequency of } \\
\text { Connectives }\end{array}$ & $\begin{array}{c}\text { Percentag } \\
\mathrm{e}\end{array}$ \\
\hline Juxtaposition & 1543 & $39.21 \%$ & 1013 & $36.28 \%$ \\
\hline Summation & 249 & $6.34 \%$ & 70 & $2.52 \%$ \\
\hline Apposition & 194 & $4.92 \%$ & 230 & $8.24 \%$ \\
\hline Causation & 703 & $17.87 \%$ & 451 & $16.13 \%$ \\
\hline Inference & 19 & $0.49 \%$ & 129 & $4.62 \%$ \\
\hline Contrast & 851 & $21.63 \%$ & 566 & $20.25 \%$ \\
\hline Transition & 77 & $1.96 \%$ & 160 & $5.74 \%$ \\
\hline Concession & 127 & $3.22 \%$ & 65 & $2.31 \%$ \\
\hline Determination & 172 & $4.36 \%$ & 109 & $3.91 \%$ \\
\hline Amount to & 3935 & $100 \%$ & 2794 & $100 \%$ \\
\hline
\end{tabular}

As shown in the table, the three categories of connectives most commonly used in the two corpora are the same. They denote juxtaposition, contrast, and causation, respectively. The three semantic categories of connectives account for almost the same proportion in the two corpora and the frequency of occurrence in the two corpora accounts for about $73 \%$ of the total frequency of connectives. Compared with Corpus II, the connectives of inference and transition in corpus I are less frequently used, while the connectives of summary relationship are more frequently used. The results show that the students of Northeast Petroleum University have a strong awareness of using different kinds of connectives to help achieve smooth connection of text content, especially in the use of connectives indicating

contrast, causation, contrast, concession and determination. However, compared with British students, their frequency of using appositives and transitional categories of connectives is insufficient, and the frequency of summarizing categories is too frequent. This result is consistent with previous research to some extent. Altenberg \&Tapper found that Swedish English learners used the most conjunction words in juxtaposition and contrast, while transitional and inferential relations were rarely used. In order to understand the differences in the use of conjunctions in the writing of non-English majors in Northeast Petroleum University one year ago and one year later, we compared the CET- 4 simulated composition samples 
1 and 2 of these students one year ago and one year later. The results are shown in the following table:

Table 4. Frequency of Connectives Used in the Two Samples

\begin{tabular}{|l|l|l|l|l|}
\hline \multirow{2}{*}{ Category } & \multicolumn{2}{|c|}{ Sample 1 } & Sample 2 & \\
\cline { 2 - 5 } & Frequency & Percentage & Frequency & Percentage \\
\hline Juxtaposition & 837 & $37.99 \%$ & 706 & $40.76 \%$ \\
\hline Summation & 158 & $7.17 \%$ & 91 & $5.25 \%$ \\
\hline Apposition & 112 & $5.08 \%$ & 82 & $4.73 \%$ \\
\hline Causation & 368 & $16.70 \%$ & 335 & $19.34 \%$ \\
\hline Contrast & 537 & $24.38 \%$ & 314 & $18.13 \%$ \\
\hline Concession & 48 & $2.18 \%$ & 79 & $4.56 \%$ \\
\hline Transition & 45 & $2.04 \%$ & 32 & $1.85 \%$ \\
\hline Determination & 87 & $3.94 \%$ & 85 & $4.91 \%$ \\
\hline Inference & 11 & $0.50 \%$ & 8 & $0.46 \%$ \\
\hline Amount to & 2203 & $100 \%$ & 1732 & $100 \%$ \\
\hline
\end{tabular}

It can be seen from Table 4 that coordinate connectives, contrastive connectives and causal connectives are the three most frequently used connectives in the two samples. In sample 1 , the above three types of connectives account for $79.07 \%$ of all connectives, and in sample 2, they account for $78.23 \%$. The frequency of the occurrence of these three types of connectives is basically the same in both samples. The proportions of causal connectives and concession connectives in sample 1 were $16.70 \%$ and $2.18 \%$ respectively, while in sample 2 , the proportions of these two types of connectives were $19.34 \%$ and $4.56 \%$ respectively. We found that after a year of study, students were more likely to use causal and concessional connectives. And the number of connectives used by students in writing did not increase, but decreased. This may be caused by a variety of reasons, such as teachers' guidance and students' attitude towards writing. In order to further understand the causes of the current situation of students' using connectives, the author carried out a questionnaire among 120 college students. The reasons are summarized as follows:

First of all, students' attitude towards English learning and English writing is not positive. The first four questions of the questionnaire are designed to investigate students' attitudes towards English learning and English writing. Only $19.17 \%$ of the students think English writing is the most important skill in English writing. Most of the students' writing attitude is blind, which affects the quality of their writing to a great extent. According to the results of the questionnaire, only $17 \%$ of the students think English writing is very important; $58 \%$ of students rated writing as medium in importance. Even $11.67 \%$ of the students think English writing is not important at all. This problem is very serious and should be taken seriously. If students are not willing to write, it is difficult to improve the quality of writing.

Secondly, English teachers do not give students correct guidance on the use of cohesion and connectives. $33.3 \%$ of the students believe that their English teachers always pay attention to the cohesion within sentences during teaching, $42.5 \%$ believe that English teachers often pay attention to the cohesion between sentences, and $43.33 \%$ say that their English teachers often pay attention to the cohesion of different paragraphs. This shows that some English teachers tend to ignore the use of cohesion and connectives when commenting on compositions. Teachers neglect the use of cohesion and connectives in teaching, so that students have little awareness of cohesion in texts.

Moreover, the students think the way of correcting the composition is not very ideal. This questionnaire aims to explore students' attitudes towards the way teachers mark essays and how students would like their essays to be marked and commented on. $32.5 \%$ of the students thought their English teachers paid more attention to structure and content, while $40.83 \%$ thought their English teachers paid more attention to grammatical errors and word spelling. These results show that most English teachers pay more attention to grammar and spelling when correcting students' compositions.

\section{CONCLUSIONS}

Based on the self-built corpus, this study first made a comparative analysis of the use of connectives by non-English majors in Northeast Petroleum University and also by native English college students, and then 
compared the use of connectives in those non-English majors' compositions of the previous year and the following year. The differences in the results provide some enlightenment for Chinese students' English learning and teachers' teaching. First, we should pay attention to cultivate students' positive attitude towards writing.

The first step is to enable students realize the importance of writing, because the improvement of writing level is closely related to the improvement of comprehensive language ability. Teachers should try to cultivate students' interest in writing and let students enjoy the process of writing instead of being scared of it. Second, English teachers should give attention to the cultivation of students' English thinking mode. Let the students know the difference between Chinese thinking and English thinking. In fact, there are huge differences between the two cultures and ways of thinking. Generally speaking, Chinese emphasizes "meaning" while English emphasizes "form". College students have mastered basic vocabulary and have the ability to think positively. If English teachers give students the right guidance at the right time, they can make great progress in this area. English teachers often ignore the importance of textual knowledge in teaching. However, text awareness and text knowledge play an important role in improving students' writing ability. Therefore, Third, English teachers should pay more attention to improving students' discourse awareness and competence in daily teaching. We are trying to impart the knowledge of discourse to the students, and at the same time let the students know that, in fact, the coherence of discourse is not always realized by connectives. Fourth, English teachers should pay heed to the output of students' language. It is of profound significance for students to have enough different forms of language output both in and out of class. Output, as a process of language learning, can also promote language learning, so teachers should pay attention to encourage students to write more. Fifth, English teachers should strive to improve students' stylistic awareness, let students understand different stylistic forms, help students master the different stylistic features of different connectives in class, so that students can distinguish between spoken and written English style; After class, students should be encouraged to practice using more complex sentences, such as prepositional phrases and clauses, which will help students write more formal or academic essays.

\section{REFERENCES}

[1] Allard, L. \& K. Ulatowske. Cohesion in Written Narrative and Procedural Discourse of Fifth-grade Children [J]. Linguistics and Education. 3 (1991): 63-79.

[2] Altenberg B, Tapper M. The Use of Adverbial Connectors in Advanced Swedish Learners' Written English [M]. London \& New York: Addison Wesley Longman, 1998: 80-93.

[3] Byrne, D. Teaching Writing Skills [M]. London: Longman, 1979:21.

[4] Granger S, Tyson S. Connector Usage in the English Essay Writing of Native and Non-native EFL Speakers of English [J]. World English. 15 (1996):17-27.

[5] Halliday, M.A.K. \& Hasan, R. Language, Context and Text $[\mathrm{M}]$. Victoria: Deakin University Press, 1985: 36, 104.

[6] Halliday, M. A. K. \& R. Hasan. Cohesion in English [M]. London: Longman, 1976: 36, 76-79, 140.

[7] Quirk, R., et al. A Comprehensive Grammar of English [M]. London: Longman, 1985: 69, 636-638.

[8] Hu Zhuanglin. Discourse Cohesion and Coherence [M]. Shanghai: Shanghai Foreign Language Education Press. 1999: 72-89,

[9] Zhao Weishan. A Qualitative Contrastive Analysis of the Use of Logical Connectives in English Compositions by Chinese Students [J]. Foreign Language Teaching, 2018(2):72-76.

[10] Li Xiaoxia. A Corpus-Based Study on the use of Connectives in Argumentative Writing of English Majors (J). Journal of Guangdong Institute of Petrochemical Technology, 2013, (8):91-94.

[11] Song Liyuan, Gao Lili.A Comparative Study on the Use of Connectives Based on Learners' Corpus (J). Journal of Hubei Second Normal University, 2020, (1): 24-29.

[12] Zhao Min, Fengxia. A Study on the Use of Connectives in Argumentative English Writing 
by Engineering College Students [J]. Foreign Language World. 2015 (5): 9-15.

[13] Zhangrui, Lv Changhong. Research on the Application of Sequential Connectives for English Learners Based on TECCL and LOCNESS Corpus (J). Journal of Changji University, 2019, (5):36-39. 